\section{H.K. Yip ${ }^{1 *}$, J. Guo ${ }^{2}$, and W.H.S. Wong ${ }^{3}$}

${ }^{1}$ Faculty of Dentistry, The University of Hong Kong, Room 1A23, Prince Philip Dental Hosptial, 34 Hospital Road, Hong Kong SAR, China; ${ }^{2}$ Oral Biomedical Engineering, School \& Hospital of Stomatology, Wuhan University, Wuhan 430079, China; and ${ }^{3}$ Division of Biostatistics, Department of Pediatric and Adolescent Medicine, Faculty of Medicine, The University of Hong Kong, Pokfulam; *corresponding author, hkyip@hkucc.hku.hk

J Dent Res 86(5):431-435, 2007

\title{
Protection Offered by Root-surface Restorative Materials against Biofilm Challenge
}

\section{INTRODUCTION}

D ental caries and periodontal disease are associated with changes in the metabolism and composition of the oral flora at specific sites. Because conditions within the mouth are never stable for long periods, many in vivo environmental conditions are difficult to control and manipulate. Although biofilms in in situ studies have been reported to be consistent within an individual, they varied significantly among individuals (Arweiler et al., 2004; Moura et al., 2004). In vitro studies can be advantageous, because most of the environmental conditions and the microbiota can be controlled and changed (Sissons, 1997).

The characteristics of biofilms formed by major cariogenic microorganisms in the artificial mouth have been shown to be similar to those of dental plaque on the surfaces of roots with caries (Shu, 1988). When a biofilm is allowed to form on enamel and dentin in vitro, the demineralization observed is similar to that in a natural caries lesion (Shu et al., 2000). Fontana et al. (2004) showed that biofilm development was associated with 5 cariogenic micro-organisms and the depth of demineralization in enamel. They also found that, although sucrose 'feeding time' did not affect lesion size, the frequency of sucrose feeding did.

There has so far been no study of the effects of mixed-species oral biofilms formed by major cariogenic micro-organisms on the surfaces of restored roots, despite the increased prevalence of root-surface caries (Griffin et al., 2004). The objective of this study was to conduct an elemental analysis of the mineral content of the surfaces of restored roots under a simulated oral biofilm generated in an artificial mouth culture system. Fluoride has been shown to move across the biofilm in vivo (Watson et al., 2005), so this study used fluoride-depleted specimens to minimize the effect of fluoride diffusion in the biofilm between the surface of the restorative material and the root surface. The first null hypothesis was that restorative materials have no effect on the root surface under the oral biofilm generated in an artificial mouth. The second null hypothesis was that restorative materials confer the same therapeutic effect on the enamel and root surface.

\section{MATERIALS \& METHODS}

\section{Restorative Materials}

Three restorative materials were compared: resin composite, resin-modified glass-ionomer cement, and glass-ionomer cement. The types, compositions, and fluoride-release and fluoride-depletion times of restoratives used are given in the Table.

\section{Biofilm Formation on Restored Root Surfaces}

Twenty-four sound, extracted human third molars were supplied by the oral and maxillofacial surgery unit of the Prince Philip Dental Hospital, The University of Hong Kong. The use of human tissues followed an approved protocol that satisfied

Received February 22, 2006; Last revision December 15, 2006; Accepted January 1, 2007 
Table. Characteristics of Restorative Materials Used

\begin{tabular}{|c|c|c|c|c|c|}
\hline Tooth Tissue or Restorative & Manufacturer & Shade & Composition & $\begin{array}{l}\text { Wavenumber } \\
\left(\mathrm{cm}^{-1}\right)\end{array}$ & $\begin{array}{l}\text { Chemical Group } \\
\text { (range, } \mathrm{cm}^{-1} \text { ) }\end{array}$ \\
\hline \multirow[t]{4}{*}{$\begin{array}{l}\text { Resin composite } \\
\text { Filtek Supreme (syringe) }\end{array}$} & \multirow[t]{4}{*}{$\begin{array}{l}\text { 3M-ESPE, } \\
\text { St. Paul, MN, USA }\end{array}$} & \multirow[t]{4}{*}{ A3 } & \multirow{2}{*}{$\begin{array}{l}\text { Bisphenol-A-polyethylene glycoldiether dimethacrylate, } \\
\text { trimethylene glycol dimethacrylate, zirconium oxide, } \\
\text { silica fillers }(4 \%, w / w) \text {, photoinitiator (trace). }\end{array}$} & 837 & $\begin{array}{l}\text { C-H "oop" in aromatics } \\
(900-675)\end{array}$ \\
\hline & & & & 1265 & $\begin{array}{l}\text { C-O-C stretch } \\
1250-1310\end{array}$ \\
\hline & & & $\begin{array}{l}\text { Fluoride release rates (Vermeersch et al., 2001): } \\
\text { 1-day: } 0.00 \mu \mathrm{g} / \mathrm{mm}^{2} / \text { day }\end{array}$ & 1741 & $\begin{array}{c}\mathrm{C}=\mathrm{O} \text { stretch in esters } \\
(1750-1735)\end{array}$ \\
\hline & & & 90-day: $0.00 \mu \mathrm{g} / \mathrm{mm}^{2} /$ day & 1870 & Unknown \\
\hline \multirow[t]{3}{*}{$\begin{array}{l}\text { Resin-modified glass-ionomer } \\
\text { cement Photac-Fil (capsule) }\end{array}$} & \multirow[t]{3}{*}{$\begin{array}{l}\text { 3M-ESPE, } \\
\text { Seefeld, Germany }\end{array}$} & \multirow[t]{3}{*}{ A3 } & $\begin{array}{l}\text { Powder: Sodium-calcium-aluminum-fluoro-silicate-glass } \\
\text { Liquid: (1) Acrylic and maleic acid copolymer }\end{array}$ & 796 & $\begin{aligned}= & \mathrm{C}-\mathrm{H} \text { bend in alkenes } \\
& (1000-650)\end{aligned}$ \\
\hline & & & $\begin{array}{l}\text { (2) Glass-ionomer compatible monomer and oligomer } \\
\text { (3) Camphor quinone }\end{array}$ & 1220 & $\begin{array}{l}\text { C-O stretch in esters } \\
(1310-1250)\end{array}$ \\
\hline & & & $\begin{array}{l}\text { (4) Water } \\
\text { Fluoride release rate (Vermeersch et al., 2001): } \\
\text { 0-day: } 0.13 \mu \mathrm{g} / \mathrm{mm}^{2} / \text { day } \\
\text { 90-day: } 0.00 \mu \mathrm{g} / \mathrm{mm}^{2} / \text { day }\end{array}$ & 1735 & $\begin{array}{c}\mathrm{C}=\mathrm{O} \text { stretch in esters } \\
(1750-1735)\end{array}$ \\
\hline \multirow[t]{3}{*}{$\begin{array}{l}\text { Glass-ionomer cement } \\
\text { Ketac-Molar Applicap (capsule) }\end{array}$} & \multirow[t]{3}{*}{$\begin{array}{l}\text { 3M-ESPE, } \\
\text { Seefeld, Germany }\end{array}$} & \multirow[t]{3}{*}{ A3 } & $\begin{array}{l}\text { Powder: calcium aluminum-lanthanum-fluorosilicate glass, } \\
\text { acrylic acid-maleic acid copolymer, pigments }\end{array}$ & 1217 & $\begin{array}{l}\text { C-O stretch in esters } \\
(1310-1205)\end{array}$ \\
\hline & & & $\begin{array}{l}\text { Liquid: water, acrylic acid-maleic acid copolymer, } \\
\text { tartaric acid }\end{array}$ & 1450 & $\begin{array}{l}\text { C-H stretch in alkanes } \\
\text { (1470-1450) }\end{array}$ \\
\hline & & & $\begin{array}{l}\text { Fluoride release rate (Vermeersch et al., 2001): } \\
\text { 0-day: } 1.05 \mu \mathrm{g} / \mathrm{mm}^{2} / \text { day } \\
\text { 90-day: } 0.00 \mu \mathrm{g} / \mathrm{mm}^{2} / \text { day }\end{array}$ & 1685 & $\begin{array}{l}\mathrm{C}=\mathrm{O} \text { stretch in alpha, } \\
\text { beta-unsaturated } \\
\text { aldehydes (1710-1665) }\end{array}$ \\
\hline
\end{tabular}

the requirement of the IRB, Faculty of Dentistry, The University of Hong Kong, and informed patient consent was obtained.

One cavity $\left(3 \times 3 \times 3 \mathrm{~mm}^{3}\right)$ was prepared midway across the enamel-cementum junction in each of the 24 teeth selected, with 6 teeth in each of the 3 restorative groups. The restored teeth were individually bottled and aged in water (replenished) at room temperature for $3 \mathrm{mos}$, to allow the fluoride content to be depleted and absorbed into the enamel and root sides adjacent to the restorations. The aged teeth were then sectioned into cubes containing the restoration (each side measuring $5 \mathrm{~mm}$ ), by means of a diamond-impregnated disc (Isomet; Buehler Ltd., Lake Bluff, IL, USA) under water cooling. Two of each type of restorative material were randomly assigned to 1 microstation, and 6 tooth specimens in total were embedded in 1 epoxy resin block at $60^{\circ} \mathrm{C}$ for $48 \mathrm{hrs}$ (TAAB 812 resin; TAAB Laboratories, Aldermaston, UK). The surfaces of each epoxy resin block were polished with 600-grit sandpaper to give a flat surface, and the blocks were sterilized overnight with $2 \%$ glutaraldehyde. Four blocks were placed in 4 biofilm holders, each housed in microstations of an artificial mouth culture system. Under computer control, sucrose $(5 \%, \mathrm{w} / \mathrm{v})$ was supplied every $8 \mathrm{hrs}$ for $6 \mathrm{~min}$, and the basal medium mucin (BMM) was supplied continuously at $0.2 \mathrm{~mL} / \mathrm{min}$ throughout the experimental period (Wong and Sissons, 2001). Biofilms were created on tooth specimens with 4 bacterial species-namely, Streptococcus mutans, Streptococcus sobrinus, Lactobacillus rhamnosus, and Actinomyces naeslundii (Shu et al., 2000). Bacterial inoculation was performed on days 1,3 , and 5 to facilitate the establishment of all bacterial species, which were incubated at $37^{\circ} \mathrm{C}$ and $100 \%$ humidity. At the end of day 21 , the bacterial compositions of the inoculum and the biofilm were analyzed. Gram stain, catalase test results, and total microbiological counts confirmed the bacterial species similarity of the oral biofilms (Shu et al., 2000; Wong and Sissons, 2001). Each tooth sample was sectioned midway across the restoration, along the long axis of the restored tooth specimen. One half of the specimen was used for Fourier transform infrared (FTIR) spectroscopy, and the other was used for scanning electron energy-dispersive spectroscopy (SEMEDS). The root/enamel sides were compared because the lesion was created on both sides of the restorative materials.

\section{Scanning Electron Microscopy}

The objective of SEM-EDS was to study the changes in mineral content (in terms of log calcium-to-phosphorus $\mathrm{Ca}: \mathrm{P}$ ratio) of calcified tooth tissue in the demineralized area under the biofilm generated on the restored root surface in the artificial mouth. The restored tooth specimens were first prepared and examined under a scanning electron microscope (Gemini, Leo 1530, Germany) set at $20 \mathrm{kV}$. An assessment of the log Ca:P of demineralized and sound areas adjacent to the demineralized areas was made by energydispersive spectroscopy (model 7426; Oxford Instruments, Oxford, UK). Elemental analysis was carried out across the root surface at the restorative margin of the enamel in 3 line scans that were 30 $\mu \mathrm{m}$ apart, with the $1 \mathrm{st}$ line being $30 \mu \mathrm{m}$ from the tooth-restoration junction. Each line scan consisted of 10 points, $20 \mu \mathrm{m}$ apart (total of $10 \times 3 \times 5=150$ spot analyses for each restorative material tested and 150 internal controls for each group, giving 300 analyses). 


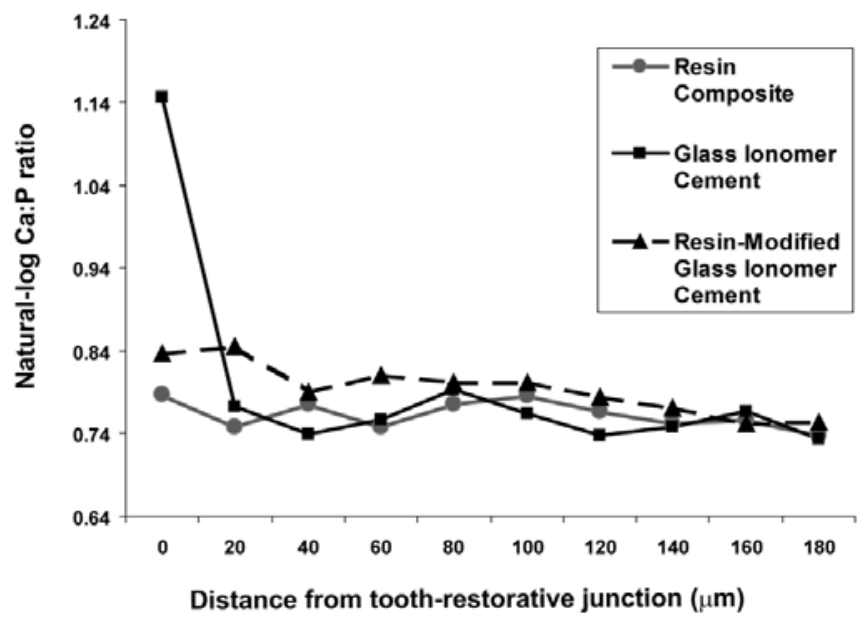

Figure 1. Mineral density (log Ca:P) of the restored root surface after 3 weeks' culture with oral biofilm. The log Ca:P was measured by energydispersive spectroscopy from the root surface to $200 \mu \mathrm{m}$ in depth (total of $10 \times 3 \times 5=150$ spot analyses for each restorative material tested and 150 internal controls for each group, giving 300 analyses). Glassionomer cement was the only material to show an increase in log $C a: P$ at the root surface adjacent to the restoration $(P<0.01)$. The log Ca: $P$ tailed off at distances farther from the interface. Such results were not found at the enamel surface.

\section{Fourier Transform Infrared Spectroscopy}

Any changes in the chemical structure of the restored tooth surface were analyzed by UMA-500 detector-equipped microscopy (BioRad Laboratories, Hercules, CA, USA). The infrared radiation used ranged from 650 to $4000 \mathrm{~cm}^{-1}$ in wavelength number. The FTIR spectrum of restored tooth specimens $(n=5$ for each restorative tested) was obtained by the average acquisition of data at the spatial resolution achieved with a $100 \times 100 \mu \mathrm{m}$ aperture.

This was based on a technique used to measure the difference between demineralized and remineralized bone (Mythili et al., 2000). The organic matrix of dentin and bone is composed mainly of type I collagen (resulting in an amide band in the FTIR spectrum), and the mineral matrix is composed of nearly the same amount of biological apatite in dentin $\left(\mathrm{HPO}_{4}{ }^{2-}\right.$ band in the FTIR spectrum) (Magne et al., 2001). The changes in mineral content were calculated on the basis of the spectrally derived matrix-tomineral ratio (the areas of absorbance of the protein amide I peak between 1585 and $1720 \mathrm{~cm}^{-1}$ to the phosphate $\left(\mathrm{HPO}_{4}{ }^{2-}\right)$ peak between 900 and $1200 \mathrm{~cm}^{-1}$ ).

\section{Statistical Analysis}

The differences between the mineral densities were assessed by one-way analysis of variance (ANOVA). We used a post hoc Tukey test to detect any significant differences between demineralized areas and sound areas in the same specimens (internal controls). Analyses were performed with SPSS software (version 13.0, SPSS Inc., Chicago, IL, USA). A 5\% significance cut-off level was used for all analyses.

\section{RESULTS}

\section{Analysis of Biofilm Bacteria}

The microbiological tests showed that the micro-organisms at the end of the 21-day experimental period were similar, and the
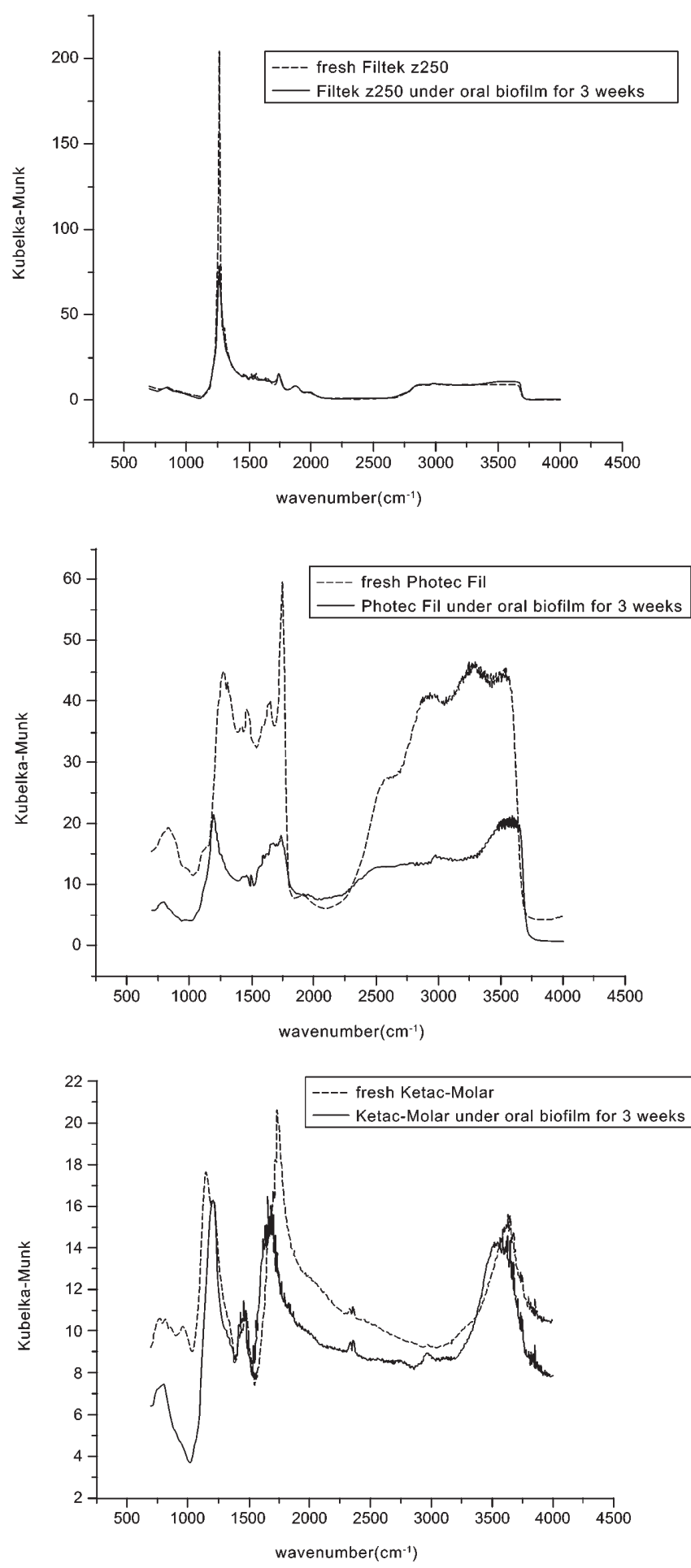

Figure 2. FTIR spectra of the restorative materials used.

bacterial loading of the oral biofilm was in the moderate range of 0.35-3.4 x 10 ${ }^{8}$. The predominant streptococcal species was S. mutans after growth competition with $\mathrm{S}$. sobrinus. The aged restoration showed negligible fluoride release (90-day: 0•00 $\mu \mathrm{g} / \mathrm{mm}^{2} /$ day; Vermeersch et al., 2001) (Table) and did not seem to have any effect on the levels of $S$. mutans or other bacteria in the oral biofilm. 


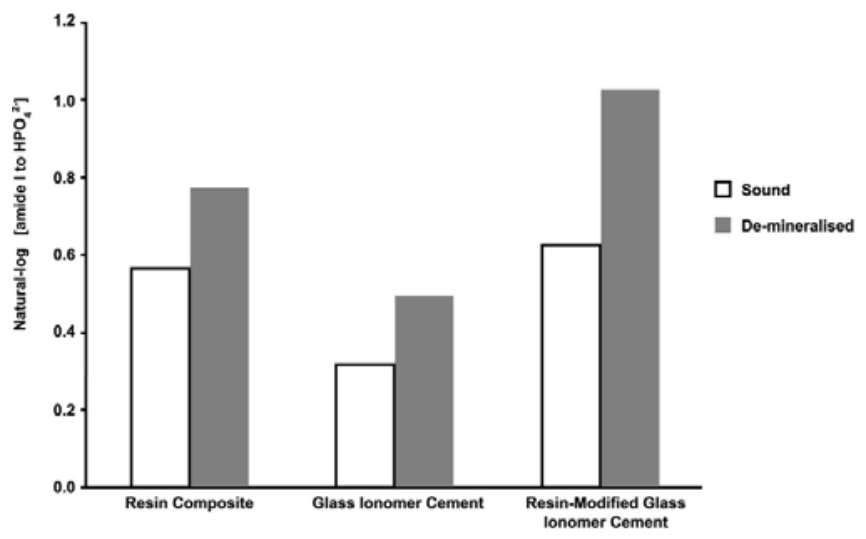

Figure 3. Log FTIR intensity ratios of amide $\mathrm{I}$ to $\mathrm{HPO}_{4}{ }^{2-}$ showing the mineral content of restored enamel and restored root surface with 3 different restorative materials (scan area: $100 \times 100 \mu \mathrm{m})(\mathrm{n}=5$ for each restorative tested). The log [amide I: $\mathrm{HPO}_{4}{ }^{2-}$ ] for glass-ionomer cement was lower than that of the other 2 materials $(P=0.04)$. The statistical analysis of the restorative materials ( $\mathrm{v} 1$ ) was: Type III sum of squares $=0.90, \mathrm{df}=2$, mean square $=0.45, \mathrm{~F}=4.19$, and sig. $=$ 0.03 . The statistical analysis of sound and demineralized tissue (v2) was: Type III sum of squares $=0.51, \mathrm{df}=1$, mean square $=0.51, \mathrm{~F}=$ 4.69 , and sig. $=0.03$. The statistical analysis of $\mathrm{vl}^{*} \mathrm{v} 3$ was: Type III sum of squares $=0.07, \mathrm{df}=2$, mean square $=0.03, \mathrm{~F}=0.32$, and sig. $=0.73$.

\section{Scanning Electron Microscopy}

After 3 weeks' culture of the mixed-species biofilm, glassionomer cement was the only restorative material that showed an increase in $\log \mathrm{Ca}: \mathrm{P}$ at the root surface adjacent to the restoration $(\mathrm{P}<0.01)$ (Fig. 1); however, this material did not significantly increase $\log \mathrm{Ca}: \mathrm{P}$ on the enamel side $(\mathrm{P}=0.72)$. The $\log \mathrm{Ca}: \mathrm{P}$ tailed off at distances farther from the restorationtooth interfaces, but the ratio was not significantly different among the restorative materials tested on the enamel side $(\mathrm{P}=$ 0.87 ) or on the root surface $(\mathrm{P}=0.89)$.

\section{Fourier Transform Infrared Spectroscopy}

The characteristics of tooth tissue and the 3 restorative materials, including their main chemical groups and FTIR spectra before and after 3 weeks' culture with a mixed-species biofilm, are shown in Fig. 2. Polymerization of liquid dimethacrylate monomers in the resin-modified glass-ionomer cement was light- and catalyst-initiated to provide a hard solid polymer; hence, the intensity of the carbonyl $(\mathrm{C}=\mathrm{O})$ band became very strong after 3 wks. Due to the different chemical compounds in the restorative materials tested, we did not attempt to identify an FTIR peak for comparison. Analysis of the overall FTIR spectral changes of the different restorative materials revealed that transmittance and peak area intensity of the glass-ionomer cement decreased after incubation in the artificial mouth. Transmittance and peak area intensity of the resin-modified glass-ionomer cement also decreased after incubation, although to a lesser extent. Resin composite was not affected after incubation with the biofilm.

Sound tissue in restored root surfaces had significantly lower $\log$ [amide I: $\mathrm{HPO}_{4}{ }^{2-}$ ] than demineralized tissue (Fig. 3). The FTIR spectrum of the root surface and enamel of control sound areas showed that the amide peaks were higher on the root surface than on enamel. The ANOVA results showed that the log [amide $\mathrm{I}: \mathrm{HPO}_{4}{ }^{2-}$ ] on the root surfaces of glass-ionomer restorations was significantly lower than those of the other 2 materials $(\mathrm{P}=0.04)$ (Fig. 3), and that the $\log$ [amide I: $\mathrm{HPO}_{4}{ }^{2-}$ ] of the demineralized surface was lower than that of the control sound tooth surface $(\mathrm{P}=0.03)$.

\section{DISCUSSION}

Our study simulated a high-caries-risk situation where oral biofilm received no intervention from oral therapeutic agents for a 21-day experimental period. The findings showed that fluoride-depleted glass-ionomer cement conferred a therapeutic and preventive effect on the root surface, but not the enamel, against initial cariogenic challenge from a mixed-species oral biofilm generated in an artificial mouth. The anticariogenic effect of the glass-ionomer cement may be related to its ability to inhibit demineralization by fluoride release. However, fluoride-depleted resin-modified glass-ionomer cement also released fluoride, but did not confer a therapeutic or preventive effect on either side of the restored root surface. However, we cannot eliminate the possibility of an antimicrobial effect on the restorations from substances other than fluoride. We previously demonstrated that one glass-ionomer cement showed the penetration of strontium and fluoride into dentin (Smales et al., 2005).

Fluoride-releasing restorative materials have been found to inhibit demineralization of the enamel and root sides of the root surface (Lam et al., 1998; Gonzalez Ede et al., 2004). Interestingly, Sa et al. (2004) showed that glass-ionomer cement was not anticariogenic in human root dentin cultured in a microbial model with $S$. mutans and $L$. casei, but did show anticariogenic properties in a chemical-demineralizing model. Different combinations of cariogenic oral micro-organisms indeed affect the demineralization of the root surface differently (Shen et al., 2004).

We observed a drop in transmittance and peak area intensity across the FTIR spectrum of glass-ionomer cement and, to a lesser extent, across that of resin-modified glass-ionomer cement after the restored root surfaces had been cultured for 3 wks under a biofilm generated in an artificial mouth. In contrast, resin composite was not affected. These results differed from those observed when an artificial saliva system was used (Yip and To, 2005), perhaps due to the different conditions of artificial saliva and mixed-species oral biofilm.

Enamel and dentin are composed of an organic matrix, a mineral matrix, and water (Bachmann et al., 2003). In enamel tissue, 2 infrared signals from the hydroxyl group can be observed: at $3570 \mathrm{~cm}^{-1}$, associated with stretching, and at 749 $\mathrm{cm}^{-1}$, associated with liberation. Root-surface and dentin specimens have profiles showing basically the same bands that differ only in their proportions - that is, the amide peaks are higher in root-surface profiles than in dentin profiles (Sasaki et al., 2002).

Presumably, acids from the oral biofilm dissolve hydroxyapatite (HAP) and expose the previously HAP-masked collagens and organic matrices, thereby generating more carbonyl groups (Di Renzo et al., 2001a). In addition, exposed collagen will be quickly attacked by bacterial protolytic enzymes (Di Renzo et al., 2001b). The altered matrix of the root side of the restored root surface of a glass-ionomer restoration was shown to be least susceptible to demineralization by the cariogenic challenge of a mixed-species oral 
biofilm generated in an artificial mouth, possibly due to the conversion of the hydroxyapatite to fluoroapatite on the root surface during the process of fluoride absorption from the restorative material. The preventive and therapeutic effects of glass-ionomer restorations may be explained by increased resistance to removal of fluoroapatite by acid on the root side, because of its significantly higher mineral content (higher log $\mathrm{Ca}: \mathrm{P})$ compared with the other restorative materials tested. Therefore, less collagen and organic matrix was exposed (lower $\log$ [amide I to $\mathrm{HPO}_{4}{ }^{2-}$ ]) to cariogenic challenge by the mixedspecies oral biofilm. All restorative materials tested did not significantly alter the mineral content and organic matrices on the enamel side of the restored root surface.

Our findings show that it is necessary to differentiate between caries on the enamel and root sides of a restored root surface, because the preventive effect of glass-ionomer cement is restricted to the root side.

Glass-ionomer cement was the only restorative material of the 3 tested that conferred a preventive and therapeutic effect on the root surface against initial cariogenic challenge by mixed-species oral biofilm generated in an artificial mouth, simulating a high-caries-risk situation with no oral therapeutic intervention. The first null hypothesis - that restorative materials have no effect on the root surface under the oral biofilm generated in an artificial mouth-was thus rejected. The second null hypothesis - that restorative materials confer the same therapeutic effects on the enamel and root surface-is also rejected.

\section{ACKNOWLEDGMENTS}

CERG Grant No. 10202943 from the Hong Kong Research Grant Council was used to set up the artificial mouth and fund this study. We are grateful to Johnson \& Johnson Oral Health Products Division, and 3M-ESPE (Hong Kong) for nonrestrictive research grants. We are also grateful to Dr. Borong Shi, Scientific Officer, Materials Characterization and Preparation Facilities, Hong Kong University of Science and Technology, Hong Kong, for providing FTIR laboratory assistance; to Mr. Frankie Chan, EM Unit, and The University of Hong Kong, for assistance with SEM-EDS analysis; and to Dr. John Bacon-Shone and Mr. Timothy Jim, Social Service Research Centre, The University of Hong Kong, for expert statistical analysis, and Dr. Trevor Lane for preparation of manuscript.

\section{REFERENCES}

Arweiler NB, Hellwig E, Sculean A, Hein N, Auschill TM (2004). Individual vitality pattern of in situ dental biofilms at different locations in the oral cavity. Caries Res 38:442-447.

Bachmann L, Diebolder R, Hibst R, Zezell DM (2003). Infrared absorption bands of enamel and dentin tissues from human and bovine teeth. App Spectroscopy Rev 38:1-14.

Di Renzo M, Ellis TH, Sacher E, Stangel I (2001a). A photoacoustic FTIRS study of the chemical modifications of human dentin surfaces: I. Demineralization. Biomaterials 22:787-792.

Di Renzo M, Ellis TH, Sacher E, Stangel I (2001b). A photoacoustic FTIRS study of the chemical modifications of human dentin surfaces: II. Deproteination. Biomaterials 22:793-797.

Fontana M, Haider A, Gonzãlez-Cabezas C (2004). Caries lesion development and biofilm composition responses to varying demineralization times and sucrose exposures. Biofilms 1:229-237.

Gonzalez Ede H, Yap AU, Hsu SC (2004). Demineralization inhibition of direct tooth-colored restorative materials. Oper Dent 29:578585 .

Griffin SO, Griffin PM, Swann JL, Zlobin N (2004). Estimating rates of new root caries in older adults. J Dent Res 83:634-638.

Lam WTC, Yip HK, Smales RJ (1998). Fluoride release and inhibition of enamel demineralization by aesthetic restorative materials. Asian J Aesthet Dent 6:3-7.

Magne D, Weiss P, Bouler JM, Laboux O, Daculsi G (2001). Study of the maturation of the organic (type I collagen) and mineral (nonstoichiometric apatite) constituents of a calcified tissue (dentin) as a function of location: a Fourier transform infrared microspectroscopic investigation. J Bone Miner Res 16:750-757.

Moura JS, Lima EM, Paes Leme AF, Del Bel Cury AA, Tabchoury CP, Cury JA (2004). Effect of luting cement on dental biofilm composition and secondary caries around metallic restorations in situ. Oper Dent 29:509-514.

Mythili J, Sastry TP, Subramanian M (2000). Preparation and characterization of a new bioinorganic composite: collagen and hydroxyapatite. Biotechnol Appl Biochem 32(Pt 3):155-159.

Sa LT, Gonzalez-Cabezas C, Cochran MA, Fontana M, Matis BA, Moore BK (2004). Fluoride releasing materials: their anticariogenic properties tested in in vitro caries models. Oper Dent 29:524-531.

Sasaki KM, Aoki A, Masuno H, Ichinose S, Yamada S, Ishikawa I (2002). Compositional analysis of root cementum and dentin after Er:YAG laser irradiation compared with $\mathrm{CO}_{2}$ lased and intact roots using Fourier transformed infrared spectroscopy. $J$ Periodontal Res 37:50-59.

Shen S, Samaranayake LP, Yip HK (2004). In vitro growth, acidogenicity and cariogenicity of predominant human root caries flora. $J$ Dent 32:667-678.

Shu M (1998). Study of root caries in an artificial mouth. NZ Dent $J$ 94:62-64

Shu M, Wong L, Miller JH, Sissons CH (2000). Development of multispecies consortia biofilms of oral bacteria as an enamel and root caries model system. Arch Oral Biol 45:27-40.

Sissons CH (1997). Artificial dental plaque biofilm model system. $A d v$ Dent Res 11:110-126.

Smales RJ, Ngo HC, Yip KH, Yu C (2005). Clinical effects of glass ionomer restorations on residual carious dentin in primary molars. Am J Dent 18:188-93. Erratum in: Am J Dent 18:295, 2005.

Vermeersch G, Leloup G, Vreven J (2001). Fluoride release from glass-ionomer cements, compomers and resin composites. J Oral Rehabil 28:26-32.

Watson PS, Pontefract HA, Devine DA, Shore RC, Nattress BR, Kirkham J, et al. (2005). Penetration of fluoride into natural plaque biofilms. J Dent Res 84:451-455.

Wong L, Sissons C (2001). A comparison of human dental plaque microcosm biofilms grown in an undefined medium and a chemically defined artificial saliva. Arch Oral Biol 46:477-486.

Yip HK, To WM (2005). An FTIR study of the effects of artificial saliva on physical characteristics of glass ionomer cements used for ART. Dent Mater 21:695-703. 